\title{
Managing acute renal failure in very low birthweight infants
}

\author{
M G Coulthard, Bryan Vernon
}

Over recent years there has been a great increase in the survival of very low birthweight (VLBW) babies, and up to $8 \%$ of these might be expected to develop acute renal failure. ${ }^{12}$ Few such infants have primary renal disease; in most it is secondary to other serious medical or surgical conditions, including birth asphyxia, hyaline membrane disease, necrotising enterocolitis, and major cardiac surgery. ${ }^{2-11}$ Most infants with acute renal failure can be successfully managed by careful attention to fluid and electrolyte balance, but in some that is not enough. A refinement in dialysis techniques has allowed some VLBW infants to be treated by peritoneal dialysis, haemodialysis or ultrafiltration. On page 162 we describe a further haemodialysis modification that is intended for use in small babies, including those weighing $1000 \mathrm{~g}$ or less.

The aims of this article are twofold: to review the diagnosis and management options of VLBW babies with acute renal failure; and to consider some of the ethical issues these treatments inevitably raise.

\section{Diagnosis of acute renal failure}

Acute renal failure is usually diagnosed in preterm infants by a significantly increased plasma creatinine concentration, or by oliguria, defined as an hourly urine flow of $<0.5 \mathrm{ml} / \mathrm{kg} .{ }^{56}$ Plasma creatinine in the first two days reflects maternal concentrations, and acute renal failure then may be better defined by a rising plasma creatinine. ${ }^{5}$ Incipient and established renal failure may be differentiated by the fractional excretion of sodium $\left(\mathrm{FE}_{\mathrm{Na}}\right)$ which is the fraction of the sodium filtered at the glomerulus that appears in the urine. It is readily calculated from the sodium and creatinine concentrations of a plasma $(P)$ and urine (U) sample, assuming any urine is being produced:

Department of Paediatric Nephrology, Royal Victoria Infirmary, Newcastle upon Tyne NE1 4LP M G Coulthard

Department of Primary Health Care, Medical School, Newcastle upon Tyne Reverend Bryan Vernon the acute renal failure is categorised as incipient or established renal failure. A useful test is to observe the response to frusemide, $1-5 \mathrm{mg} / \mathrm{kg}$, given after a fluid challenge where necessary. ${ }^{513-16}$ After a poor response there is no value in repeating the dose because frusemide is renally excreted and will remain in the circulation for a considerable time. Some, but not all, babies with incipient renal failure will have a diuresis; this is often maintained, and renal function usually improves. If a baby does not have a diuresis further medical treatment should be considered.

Many babies with acute renal failure develop fluid overload with peripheral and pulmonary oedema, so a volume challenge is not always appropriate. Some ill babies, however, develop increased capillary permeability which results in a reduced circulating volume and gross peripheral oedema, but no pulmonary oedema; the extent of peripheral oedema or weight gain can be misleading. Central venous pressure is the ideal guide to fluid administration, but is seldom available except after cardiac surgery. In practice, up to $20 \mathrm{ml} / \mathrm{kg}$ is usually advised in babies without clinical evidence of pulmonary oedema. 61315

A renal tract ultrasound examination is useful to exclude primary abnormalities that would benefit from specific treatment (such as urethral catheterisation for posterior urethral valves), or which might influence attitudes to management, such as recessive polycystic kidney disease. Even after a period of normal renal function an ultrasound scan is helpful for example, to exclude renal vein thrombosis.

\section{Medical treatment}

Most acute renal failure in VLBW babies is secondary to other medical or surgical problems; attention must be given to improving the primary condition. Many babies are hypotensive and require inotropic support. Dopamine infused at $2 \mu \mathrm{g} / \mathrm{kg} /$ minute may improve renal function and blood pressure, even in very sick infants. ${ }^{17}$

Although dialysis is usually started because of abnormal plasma biochemistry, especially for high potassium concentration and acidosis, it is usually a reduced urine flow that precipitates the critical problem. Oligoanuria both reduces potassium losses and limits the administration of fluid, and hence of glucose and 
bicarbonate, worsening the hyperkalaemia Babies with acute renal failure but without oliguria have a much better prognosis. ${ }^{2} 61518$ In our experience babies with large non-renal fluid losses, such as diarrhoea or from chest drains after thoractomy, can be relatively easy to manage without dialysis; the losses contain potassium and can be replaced with appropriate intravenous fluids.

It is essential to restrict fluids in oligoanuric babies to minimise oedema. Fluids with a high glucose concentration must be used to prevent hypoglycaemia and minimise catabolism; the anabolism due to the high growth rate in neonates has been described as the 'third kidney'. Phlebitis is unusual with peripheral infusions of less than $10 \%$ glucose, but central access is usually needed to infuse $20 \%$ glucose. Many drugs, including inotropes, can be administered in $20 \%$ glucose, and a daily infusion of $60 \mathrm{ml} / \mathrm{kg}$ will provide over 8 $\mathrm{mg} / \mathrm{kg} / \mathrm{minute}$ glucose. Close attention must be paid to the electrolytes administered. Though it may be possible to formulate a single intravenous fluid to administer to a baby over a day, we prefer to administer two or three fluids, each designed to balance a particular loss. Although this may appear unwieldy, it allows clear decisions to be made about changing the fluid infusion rates according to changes in losses. We administer the estimated insensible loss ${ }^{19}$ as $20 \%$ glucose without sodium (with or without added drugs). The second infusion replaces measured fluid losses volume for volume, and is prescribed according to the fluid lost; it is essential to measure and not guess the electrolyte concentrations of the losses. The third fluid is used only when the replacement of insensible plus measured losses does not provide sufficient fluid volume ('space') to meet the baby's fluid needs - for example, for glucose or drug administration. This fluid must be isonatraemic because without dialysis it will be retained; dilutional hyponatraemia is common in oliguric babies given glucose infusions with little or no sodium. Isonatraemic solutions can be tailored by adding $30 \%$ sodium chloride $(5 \mathrm{mmol} / \mathrm{ml})$ or $8.4 \%$ sodium bicarbonate $(1 \mathrm{mmol} / \mathrm{ml})$. Infusions of $20 \%$ albumin may be used to correct hypoalbuminuria, and fresh frozen plasma to correct clotting abnormalities. Appropriately modified total parenteral nutrition should be introduced after 24 hours.

If these measures are inadequate to control hyperkalaemia, there are few non-dialysis options that are safe and effective. The cardiotoxic effects of hyperkalaemia may be reduced by correcting the plasma calcium and magnesium concentrations. ${ }^{515}$ The benefits of sodium-potassium ion exchange resins may be short lived, or complicated by sodium overload, ${ }^{515}$ and they may be completely ineffective in VLBW babies. ${ }^{20} 21$ Insulin and glucose infusions have also been advocated, ${ }^{15}$ but this can cause profound hypoglycaemia. ${ }^{5} \quad \beta_{2}$ adrenoreceptor agonists reduce hyperkalaemia in older children, ${ }^{22}$ but this has not been reported in newborns.

\section{Dialysis or filtration?}

The term dialysis refers to the process of removal of plasma solutes, such as potassium and urea, by diffusion down their concentration gradients across a semipermeable membrane. It does not depend on the movement of water. The membrane may be a synthetic one with blood and dialysis fluid pumped on opposite sides (haemodialysis), or it may be the peritoneum separating the splanchnic blood from fluid instilled into the peritoneal space (peritoneal dialysis). In contrast, the term filtration refers to the removal by convection of protein free plasma water across a membrane. The filtered water contains other plasma solutes at a concentration similar to plasma and can be thought of as glomerular filtrate equivalent. The driving force for filtration may be the hydraulic pressure across a synthetic membrane generated within a blood circuit, or the osmotic pressure between plasma and dialysis fluid in peritoneal dialysis. The terms haemofiltration and haemofiltrate are sometimes used when the filtration is achieved using a blood circuit, whereas the terms ultrafiltration and ultrafiltrate describe filtration using either method. Some treatments result in pure dialysis, and some in pure filtration, but in most situations a combination of both is achieved.

The decision to dialyse a VLBW infant is usually made because medical treatment has failed, or is approaching its limits, and is usually based on acidosis, hyperkalaemia, hypoglycaemia, or pulmonary oedema. Gross truncal oedema may embarrass ventilation, but is seldom the sole indication for dialysis.

Dialysis is always invasive and must be considered with care. We usually repeat the cerebral ultrasound scan and review the neurology and overall outlook for the baby, insofar as it can be assessed, before deciding to dialyse. If the baby has a very high probability of severe mental handicap we do not treat. Though radionuclide scintigraphy scans may predict renal death by failing to show renal blood flow, ${ }^{6}$ they are impractical to arrange for sick VLBW infants in many units, and false negative results occur. ${ }^{6} 23$

Ideally, dialysis or filtration in a VLBW infant should provide continuous gentle fluid and solute clearance rather than the infrequent bursts of rapid clearance that stable older children are subjected to on standard haemodialysis. The choice of modality will depend on local expertise and preference, on any access catheters that the baby might already have, and on particular medical or surgical contraindications. Few authors disagree $^{24}$ that, where possible, peritoneal dialysis is the treatment of choice. ${ }^{57-9} 11$ 13-16 20 25-28

\section{Peritoneal dialysis}

The major advantages of peritoneal dialysis are the relatively easy access and its technical simplicity. Babies receiving peritoneal dialysis require highly skilled medical and nursing support, but can be managed by most special care nurseries with direct supervision from a 
paediatric nephrologist. Peritonitis is the biggest risk. ${ }^{7} 81329$ We examine effluent fluid daily by microscope and culture and add intraperitoneal antibiotics at the earliest suspicion.

Access for peritoneal dialysis is more difficult in VLBW infants than in older subjects. Rigid catheters can perforate the bowel, ${ }^{29}$ and the side holes of some extend so far that they have to be shortened. ${ }^{20}$ Peritoneal dialysis catheters depend on a snug skin fit to prevent leaks; the inelastic abdominal wall in VLBW babies leads to a high incidence of leakage in percutaneously and new surgically placed catheters. ${ }^{49111629}$ We have advocated percutaneous insertion of silastic 16 FG Tenckhoff catheters through a peel-away sheath after a $40 \mathrm{ml} / \mathrm{kg}$ pre-fill. ${ }^{30}$ However, the sheath overdilates the entry hole and increases the incidence of leakage, so we now insert a 13 FG Tenckhoff first, and replace it with a 16 FG Tenckhoff through the existing hole without further instrumentation if it leaks. The omentum causes more problems with peritoneal dialysis fluid drainage in babies than in older children ${ }^{931}$; we think this is also the case for VLBW babies. Peritoneal dialysis is usually considered impractical in infants after laparotomy, ${ }^{16}$ though it has been reported. ${ }^{28}$ There are no reports of its use after more complex abdominal surgery, such as the babies we describe on page 162 .

Most authors use 10 to $20 \mathrm{ml} / \mathrm{kg}$ cycle volumes initially, increasing to $40 \mathrm{ml} / \mathrm{kg}$ if tolerated. 81528 Larger volumes increase dialysis efficiency, but may splint the diaphragm. ${ }^{20}$ These volumes are smaller than the minimum needed for most automatic cyclers. However, manual circuits are readily available, and small cycle volumes mean that dialysis bags seldom need changing, so reducing the risk of peritonitis.

The large peritoneal surface area to body weight ratio in preterm infants gives a theoretical advantage, increasing dialysis efficiency. Although peritoneal dialysis is usually effective, ${ }^{4-9} 11$ it may fail in two ways. First, infants with a poor cardiac output may have insufficient gut perfusion to permit dialysis exchange; neither fluid nor solutes are removed. ${ }^{4}$ Second, infants with increased capillary permeability, perhaps following sepsis, may have increased peritoneal membrane permeability. Although this leads to more rapid solute removal, correcting hyperkalaemia very efficiently, ultrafiltration may fail. ${ }^{16}$ Removal of water depends on the peritoneal dialysis glucose creating a high osmolar gradient between plasma and dialysis fluid; an increased permeability may permit rapid glucose absorption and loss of the gradient. Hyperglycaemia is a risk, especially if a higher peritoneal dialysis glucose content is used in an attempt to produce an ultrafiltrate ${ }^{32}$; typical concentrations used are equivalent to between 76 and $214 \mathrm{mmol} / \mathrm{l}$. A high glucose fluid does not always improve ultrafiltration ${ }^{416}$; if it does it may be necessary to infuse intravenous insulin to maintain euglycaemia. ${ }^{4} 14$

Most commercial peritoneal dialysis fluids contain lactate rather than bicarbonate because of greater stability, and to avoid precipitation of calcium and magnesium. Hypoxic babies may be unable to metabolise lactate sufficiently quickly and their acidosis may worsen on dialysis. They can be dialysed with a mixture of intravenous solutions including bicarbonate; calcium and magnesium need to be given intravenously. ${ }^{1433} \mathrm{We}$ routinely start peritoneal dialysis in our sickest newborns with these bicarbonate solutions, ${ }^{13}$ but others have not found this to be necessary. ${ }^{4111620}$

\section{Haemodialysis and haemofiltration}

All haemodialysis and filtration techniques in VLBW infants should be performed continuously or frequently to avoid violent swings of fluid volume and biochemistry; few authors report using standard intermittent haemodialysis in babies. ${ }^{103435}$ All very small ultrafilters and dialysers are of hollow fibre design with parallel capillary membranes packed into a plastic cylinder. Several have good ultrafiltration and dialysis characteristics and can be used for either purpose: I will refer to them all as filters. One of the most widely used (minifilter, Amicon) ${ }^{36-41}$ has a blood priming volume of only $6 \mathrm{ml}$ and large diameter capillaries which give minimal resistance to flow, but a small membrane surface area of 0.015 $\mathrm{m}^{2}$. The larger minifilter-plus has a blood volume of $15 \mathrm{ml}$ and a surface area of $0.08 \mathrm{~m}^{2}$ because it has finer fibres in a larger cylinder. Amicon have an industrial product ${ }^{42}$ that combines the minifilter casing with minifilterplus fibres, giving a prime volume of $6 \mathrm{ml}$ and a surface area of $0.04 \mathrm{~m}^{2}$; this may be the best filter for VLBW babies.

\section{FILTRATION}

Ultrafiltration - the removal of plasma water by convection - can be used to reduce fluid overload. Because solute is removed simultaneously, ultrafiltration can also be used to adjust plasma biochemistry by removing extra volume and replacing it with fluid at appropriate electrolyte concentrations. At yet higher rates of filtration and replacement $(40 \mathrm{ml} /$ hour in a $1 \mathrm{~kg}$ baby, for example) a normal glomerular filtration rate can be simulated, but great care is needed because small errors can produce dramatic swings in biochemistry.

\section{DIALYSIS}

Because dialysis depends on solute diffusion rather than the removal of water, biochemical abnormalities may be quickly corrected; to maximise efficiency the fluid is pumped countercurrent to the blood. The ultrafiltrate volume is less easy to measure during dialysis and ultrafiltration than during pure filtration because it mixes with a much larger volume of effluent dialysis fluid. This can be overcome by controlling separately the inflow and outflow of dialysis fluid with dialysis or intravenous peristaltic pumps. 244143 The total flow is adjusted to produce the biochemical clearance required - for example, in a $1 \mathrm{~kg}$ baby, a flow of 50 
$\mathrm{ml} /$ hour and solute clearance efficiency of $80 \%$ would simulate a normal glomerular filtration rate of $40 \mathrm{ml} /$ hour, or $0.67 \mathrm{ml} / \mathrm{minute} / \mathrm{kg}$. ${ }^{13}$ The outpump is adjusted to remove the infused volume of dialysis fluid plus the desired ultrafiltrate. In the method described on page 163 the dialysis fluid can be recirculated because its volume is large compared with the baby's fluid volume; the ultrafiltrate is deduced by weighing the fluid tank.

\section{CIRCUIT CONFIGURATIONS AND ACCESS}

The names and initials used for different dialysis circuits are often confusing. ${ }^{44}$ In conventional circuits the blood flow through the filter comes directly from and returns directly to the baby's blood vessels. The flow rate has to be relatively high to permit efficient dialysis and filtration and to prevent clotting. Heparin is usually needed to prevent clotting, and most authors aim to increase the activated clotting time minimally, measured at the cotside. We are unaware of prostacycline being used for infant dialysis.

The simplest circuit consists of a filter connected between an arterial and a venous line; the baby's heart provides the energy for continuous arteriovenous haemofiltration (CAVH). ${ }^{363744}$ If fluid is also passed through the filter then dialysis is added which may increase urea clearance severalfold (CAVHD). 24373940 CAVH(D) requires a large arterial cannula and a systolic blood pressure of about $45 \mathrm{~mm} \mathrm{Hg}$ to produce adequate flow. ${ }^{1524}$ An umbilical arterial catheter may sometimes provide an easy route for access. 1024273435 Femoral arterial puncture can be prohibitive in a mature baby ${ }^{45}$; inserting an arterial line into an oedematous VLBW baby is daunting and seldom produces sufficient flow. We have seen older children require femoral artery repair after prolonged CAVHD; VLBW infants are likely to fare worse.

With only venous access a circuit with a blood pump and bubble trap must be used. This can provide continuous venovenous haemofiltration $(\mathrm{CVVH})^{38}$ to which dialysis may also be added (CVVHD). ${ }^{2441} \mathrm{~A}$ blood pump may also be needed in a CAVH(D) circuit if the blood pressure is inadequate; four of nine newborns were reported to need pump assistance, though two babies weighing $1.3 \mathrm{~kg}$ or less did not. 36373944 Some authors use two venous sites, ${ }^{27} 38$ but most use dual lumen catheters. ${ }^{1024}$ We favour a $1 \mathrm{~mm}$ internal diameter single lumen silastic central line for CVVHD in VLBW babies, using a dialyser pump in 'single-needle' mode. This is because the fluid flow rate through a tube varies with the fourth power of the radius; the flow through a single lumen is much greater than the combined flows through two lumens, each with half the radius. A $30 \mathrm{~cm}$ line, $1 \mathrm{~mm}$ internal diameter, contains a volume of only $0.24 \mathrm{ml}$; the common fluid path volume can be under $0.3 \mathrm{ml}$, so recirculation is minimal.

The syringe driven ultrafiltration/dialysis circuit (SDU(D)) described on page 163 of this journal is different in principle from standard ones. Blood is syringed to and from the baby at whatever speed is imposed by the access line, but the flow through the filter is independent of this. Because blood is syringed in both directions through the dialyser capillaries, there is not a pure countercurrent arrangement. The manual technique is tedious to perform, but an automated version is being developed.

\section{EXTRACORPOREAL VOLUMES}

By extrapolation from older patients an extracorporeal circuit of less than $10 \%$ of the total blood volume $(<8.5 \mathrm{ml} / \mathrm{kg})$ is recommended. ${ }^{24} 27$ Because VLBW infants have a high risk of needing a pumped circuit, and because the smallest conventional lines range from about 20 to $80 \mathrm{ml}, 27$ most standard circuits require priming with blood. With the SDU circuit the priming volume is $6.34 \mathrm{ml}$ plus the syringe stroke volume; even in the $630 \mathrm{~g}$ baby we describe, a $2 \mathrm{ml}$ stroke meant her extracorporeal volume was $13.6 \%$ of blood volume. We did not prime the circuit, and her clinical observations did not alter acutely when SDU was begun.

\section{BLOOD PRIMING}

Few details are available of the type of blood products used: most authors simply report using either albumin solutions, plasma, blood, or a mixture of plasma and blood. 102435364144 Warnings are given about the risk of high potassium in prime blood, even up to $20 \mathrm{mmol} / 1,2427$ but no mention is made of the $\mathrm{pH}$ or calcium concentration. We have seen a stable baby receiving CVVHD suddenly become bradycardic and die immediately after reconnection to a new circuit primed with fresh frozen plasma and packed red cells with acid-citrate-dextrose that had a normal potassium concentration. We attribute this to sudden hypocalcaemia caused by the citrate anticoagulant. Subsequent very prolonged attempts to pre-dialyse circuits failed to produce acceptable calcium or $\mathrm{pH}$ values. We have since used fresh whole blood anticoagulated with heparin to prime circuits, drawn and tested by the National Blood Service. Blood packs from 10 donors had normal haematology and biochemistry values until 12 hours, when the potassium had risen to the range 3.95 to $5.29 \mathrm{mmol} / \mathrm{l}$.

\section{Ethical considerations}

Most VLBW infants who develop acute renal failure resistant to pharmacological treatment will die without dialysis, but it is far from certain that they will live with dialysis. The treatment itself is not without hazard, and such babies remain at risk from other factors. Dialysis in these circumstances provides a ray of hope.

The preservation of life as an underlying presumption of the goals of medicine is not irrefutable, ${ }^{46}$ and the so-called right to life is not absolute. ${ }^{47}$ Given the uncertainty of 
outcome for these children, the decision whether to give or withhold consent to treatment will rest with the parents as agents for the child. Where a couple refuse consent for transfusion for their child because of adherence to the Jehovah's Witnesses doctrine, paediatricians would have no hesitation in resorting to legal action to overturn this decision, but parents may refuse treatment where they reasonably believe that it is not in the child's best interests. For VLBW children with acute renal failure, it would be hard to justify a challenge to parental choice because the issue is not clear-cut. However, we believe that, after hearing the parents' views, and after team consultation, the responsibility to make the final decision should be seen to rest with the doctor in an effort to minimise the parents' feelings of guilt.

Where do the child's best interests lie? It is hard to separate her interests from those of her parents. An enthusiastic team might sway the parents to see the choice as between certain death and a slight chance of life, but this is too simple. For many, death will still occur, but at a later date. This gives the parents a chance to touch the child, grow more fond of her, and become part of her struggle for life. Is this an act of cruelty for families whose hopes will have been raised only to be dashed? Alternatively, is this a welcome opportunity to relate, bringing greater meaning to a life, albeit for a brief period? Such a dichotomy cannot do justice to the ambivalent feelings of pain and joy which families in such a situation may experience. They may themselves be surprised by the strength of unexpected feelings which are unleashed, both positive and negative. In such cases the principles of beneficence and nonmaleficence can support either treatment option.

There may be doubts about the allocation of resources to such treatment, illustrated by a neonate in the USA who had exhausted his lifetime maximum insurance cover of $\$ 750000$ by 15 months. ${ }^{48}$ In the UK's publicly funded system there is no such transparently explicit maximum. There may be injustice in enormous expenditure on one person, but we have no agreed formula to determine what constitutes 'enormous'. By the time dialysis is considered in a VLBW neonate, typically there has already been a large financial investment, as well as an emotional commitment by staff and parents, which may create pressure to add another layer of treatment that is hard to resist. The involvement of another clinician at this stage provides the chance to pause and reassess the situation. This may hold in check the pressure to treat.

Some of the uncertainty in answering the ethical questions raised by this group of patients reflects the uncertainty of their medical outcome. Prognosis assessment is not a hard science, and doubt will persist in individual cases, however robust the group statistics. Having to deal effectively with uncertainty in clinical and ethical matters is an inevitable feature of modern medicine, ${ }^{49}$ but the reduction of uncertainty remains a sound objective.
Guidelines have been suggested for nontreatment in neonatal medicine that envisage three situations of potential disagreement between parents and clinicians. ${ }^{50}$ In the first, clinical opinion is that non-treatment cannot be justified, and refusal of consent by parents should lead to wardship proceedings. In the second, the clinical consensus is that the prognosis is so bad that continued treatment cannot be justified; parental insistence on life-prolonging treatment is neither a moral nor legal basis for compliance with their wishes. In the third, prognosis may be poor, but indeterminate enough to give the infant the benefit of the doubt where clinicians are disinclined to do so but parents are committed to treatment. There must surely be a fourth situation in which the prognosis is similarly poor but indeterminate, but the parents are unwilling to consent to treatment while clinicians feel that on balance it is worth a try. Treatment cannot be given without parental consent, and there may not be quite enough evidence to justify wardship proceedings. In such circumstances clinicians must acquiesce with as much grace as they can muster, but are likely to remain dissatisfied with the outcome. The VLBW children we have discussed may fall into either the third or fourth categories.

Roberton makes an impassioned case for treating babies over $500 \mathrm{~g}$ or 24 weeks, and does not discourage the treatment of those born as early as 22 weeks, nor of babies weighing less than 500 g. ${ }^{51}$ Although the absolute number of seriously handicapped VLBW survivors has increased in recent years, the proportion of survivors with serious handicap has not increased with the development of neonatal intensive care. ${ }^{52}$ There are few reports of VLBW infants being dialysed for acute renal failure. Two of four babies weighing 1 to $1 \cdot 5$ $\mathrm{kg}$, and 13 of 21 babies weighing less than $1 \mathrm{~kg}$ are reported to have survived peritoneal dialysis, 4691116202633 and two babies weighing 1 to $1.5 \mathrm{~kg}$ have successfully been haemodialysed. ${ }^{36} 44$ There are no cases reported of haemodialysis in babies less than 1 $\mathrm{kg}$ other than the ones on page 162 of this journal. A survey of neonatologists and paediatric surgeons in the Northern Region suggested that about five VLBW infants were, or could have been, candidates for acute dialysis in 1994; this would project to over 90 for the UK as a whole. In a similar national UK survey, paediatric nephrologists recalled treating only seven VLBW babies in 1994 .

Haemodialysis of VLBW infants is not only expensive in cash terms, but may also deflect medical and nursing time from patients who could benefit from conventional treatment, and may increase the stress and suffering for both parents and staff. This can only be justified if it can be shown to be effective. ${ }^{53} \mathrm{At}$ present the numbers are too small to judge. We propose that a registry of VLBW babies with acute renal failure and treated by haemodialysis should be set up to audit outcome and decide if treatment is justified. A negative outcome would need to be reconsidered at intervals in the light of other advances in care; 
models that show that patients are 'certain to die' will produce a self-fulfilling prophecy if they are rigidly applied and not reassessed.

We thank Drs Catherine Chapman and Huw Lloyd of the National Blood Service, Newcastle, for their enormous help in testing the quality of anticoagulated blood to prime dialysis circuits (and subsequently to organise a special donor service for babies requiring dialysis)

1 Norman ME, Asadi FK. A prospective study of acute rena failure in the newborn infant. Pediatrics $1979 ; 63: 475-9$.

2 Stapleton F, Jones D, Green R. Acute renal failure in neonates; incidence, etiology and outcome. Pediat Nephrol 1987; 1: 314-20.

3 Dauber IM, Krauss AN, Symchych PS, Auld DAM. Renal failure following perinatal anoxia. $\mathcal{f}$ Pediatr 1976; 88: 851-5.

4 Steele B, Vigneux A, Blatz S, Flavin M. Acute peritoneal dialysis in infants weighing $<1500$ g. $\mathcal{F}$ Pediatr $1987 ; 110$ 126-9.

5 Brocklebank JT. Renal failure in the newly born. Arch Dis Child 1988; 63: 991-4.

6 Chevalier RL, Campbell F, Brenbridge ANAG. Prognostic factors in neonatal acute renal failure. Pediatrics $1984 ; 74$ 265-72.

7 Matthews DE, West KW, Rescorla FJ, Vane DW, Grosfield $\mathrm{JL}$, Wappner RS, et al. Peritoneal dialysis in the first 60 days of life. $\mathcal{F}$ Ped Surg 1990; 25: 110-6.

8 Blowey DL, McFarland K, Alon U, McGraw-Houchens M, Hellerstein S, Waraday B. Peritoneal dialysis in the neonatal period: outcome data. $f$ Perinatol 1993; 13: 59-64.

9 Huber R, Fuchshuber A, Huber P. Acute peritoneal dialysis in preterm newborns and small infants: surgical management F Ped Surg 1994; 29: 400-2.

10 Sadowski R, Harmon W, Jabs K. Acute hemodialysis of infants weighing less than five kilograms. Kidney Int 1994 45: $903-6$

11 Zaramella P, Andreetta B, Zanon G, Murer L, Montini G, Cantarutti $F$, et al. Continuous peritoneal dialysis in newborns. Perit Dial Int 1994; 14: 22-5.

12 Mathew OP, Jones AS, James E, Bland H, Groshong T. Neonatal renal failure: usefulness of diagnostic indices. Pediatrics 1980; 65: 57-60.

13 Coulthard MG. Renal function. In: Harvey D, Cooke R, Levitt G, eds. The baby under $1000 \mathrm{~g}$. $1 \mathrm{st}$ edn. London: John Wright, 1989: 211-25.

14 Rigden SPA, Barratt TM, Dillon MJ, De Leval M, Stark J. Acute renal failure complicating cardiopulmonary bypass Acute renal failure complicating cardiopulm
surgery. Arch Dis Child 1982; 57: 425-30.

15 Karlowicz MG, Adelman RD. Acute renal failure in the neonate. Clin Perinatol 1992; 19: 139-58.

16 Sizun J, Giroux J, Rubio S, Guillois B, Alix D, De Parscau L. Peritoneal dialysis in the very low-birth-weight neonate (less than 1000 g). Acta Paediatrica 1993; 82: 488-9.

17 Seri I, Rudas G, Bors Z, Kanyicska B, Tulassay T. Effect of low-dose dopamine infusion on cardiovascular and renal functions, cerebral blood flow, and plasma catecholamine levels in sick preterm neonates. Ped Res 1993 34: 742-9.

18 Grylack L, Medani C, Hultzen C, Sivasubramanian K, Davitt MK, Jose $\mathrm{P}$, et al. Nonoliguric acute renal failure in the newborn. Am $\mathcal{F}$ Dis Child 1982; 136: 518-20.

19 Lorenz JM, Kleinman LI, Klotagal UR, Reller MD. Water balance in very-low-birth-weight infants: relationship to bater and sodium intake and effect on outcome. $\mathcal{F}$ Pediatr water and sodium inta

20 Kanarek KS, Root E, Sidebottom RA, Williams PR Successful peritoneal dialysis in an infant weighing less than 800 grams. Clin Pediatr 1982; 21: 166-9.

21 Malone TA. Glucose and insulin versus cation-exchange resin for the treatment of hyperkalemia in very low birth weight infants. F Pediatr 1991; 118: 121-3.

22 McClure RJ, Prasad VK, Brocklebank JT. Treatmen of hyperkalaemia using intravenous and nebulised salbutamol. Arch Dis Child 1994; 70: 126-8.

23 Avner ED, Heyman $S$, Treves $S$, Ingelfinger JR Radionuclide renal scintiscans and flow studies in pediatric patients with acute renal failure (ARF). Kidney Int 1979; 16: 877 .

24 Bunchman TE, Donckerwolcke RA. continuous arterialvenous diahemofiltration and continuous veno-venous diahemofiltration in infants and children. Pediatr Nephrol 1994; 8: 96-102

25 Blatz S, Paes B, Steele B. Peritoneal dialysis in the neonate. Neonatal Network 1990; 8: 41-4.

26 Shostak A, Smilovich L, Mogilner G, Raich D, Siprovich L Gotlob L. Peritoneal dialysis and recovery from acute renal failure in a 847-gram newborn infant. Perit Dial Int 1990; 10: 183-4.

27 Donckerwolcke RA, Bunchman TE. Hemodialysis in infants and small children. Pediatr Nephrol 1994; 8: 103-6.

28 Mattoo TK, Ahmad GS. Peritoneal dialysis in neonates after major abdominal surgery. Am f Nephrol 1994; 14: 6-8.

29 Lewis MA, Houston IB, Postlethwaite RJ. Access for peritoneal dialysis in neonates and infants. Arch Dis Child 1990; 49: 44-7.

30 Lambert H, Morris KP, Sharp J, Coulthard MG. Access for peritoneal dialysis in neonates and infants. Arch Dis Child 1990; 65: 914-5.

31 Clark KR, Forsythe JLR, Rigg KM, Sharp J, Rangecroft L Wagget $\mathrm{J}$, et al. Surgical aspects of chronic peritoneal dialysis in the neonate and infant under 1 year of age. f Ped Surg 1992; 27: 780-3.

32 Gruskin AB. Why is it difficult to achieve ultrafiltration in neonates who are undergoing peritoneal dialysis? Pediatr Nephrol 1989; 3: 289.

33 Nash MA, Russo JC. Neonatal lactic acidosis and renal failure: The role of peritoneal dialysis. $\mathcal{F}$ Pediatr $1977 ; 91$ 101-5.

34 Hodson EM, Kjellstrand CM, Mauer SM. Acute renal failure in infants and children: outcome of 53 patients requiring hemodialysis treatment. $\mathcal{f}$ Pediatr 1978; 93: 756-61.

35 Bock GH, Campos A Thompson $T$, Maher SM Kjellstrand CM. Hemodialysis in the premature infant. Am 7 Dis Child 1981; 135: 178 80 .

36 Lieberman KV, Nardi L Bosch JP. Treatment of acute renal failure in an infant using continuous arteriovenous remofiltration. $f$ Pediatr 1985 ; 106: 646-8.

37 Heney D, Brocklebank JT, Wilson N. Continuou arteriovenous haemofiltration in the newlyborn with acut renal failure and congenital heart disease. Nephrol Dial Transplant 1989; 4: 870-6.

38 Yorgin P, Krensky A, Tune B. Continuous venovenous hemofiltration. Pediatr Nephrol 1990; 4: 640-2.

39 Zobel G, Kuttnig M, Ring E. continuous arteriovenous hemodialysis in critically ill infants. Child Nephrol Uro 1990; 10: 196-8.

40 Bishof NA, Welch TR, Strife F, Ryckman C. Continuous hemodiafiltration in children. Pediatrics 1990; 85: 819-23.

41 Bradbury MG, Brocklebank JT, Dyson EH, Goutcher E, Cohen AT. Volumetric control of continuous haemodialysis in multiple organ failure. Arch Dis Child 1995; 72: $42-5$.

42 Coulthard MG, Sharp J. Haemodialysis and ultrafiltration in babies weighing under 1000 g. Arch Dis Child 1995; 73: F162-5.

43 Coulthard MG. Clearance and pump control of continuous arteriovenous haemodialysis. Lancet 1988; ii: 1249.

44 Schroder C, Severijnen R, Potting C. Continuous arteriovenous hemofiltration (CAVH) in a premature newborn as treatment of overhydration and hyperkalemia due to sepsis. Eur F Ped Surg 1992; 2: 368-9.

45 Paret G, Cohen AJ, Bohn DJ, Edwards H, Taylor R, Geary $\mathrm{D}$, et al. Continuous arteriovenous hemofiltration after cardiac operations in infants and children. $f$ Thorac Cardiovasc Surg 1992; 104: 1225-30.

46 Airdale NHS Trust v Bland (1993) 1 All ER 858, HL

47 R v Cambridge Health Authority ex parte B. (1995) 2 All ER 129, CA.

$48 \mathrm{Currier} \mathrm{H}$. Ethical issues in the neonatal patient with endstage renal failure. Fournal of Perinatal and Neonatal Nursing 1994; 8: 74-8.

49 Seedhouse D. Avoiding the myths: a prerequisite for teaching ethics. Postgraduate Education for General Practice 1992; 3: 117-24.

50 Doyal L, Wilsher D. Towards guidelines for withholding and withdrawal of life prolonging treatment in neonata medicine. Arch Dis Child 1994; 70: F66-70.

51 Roberton NRC. Should we look after babies less than 800 g? Arch Dis Child 1993; 68: 326-9.

52 Blackman JA. Neonatal intensive care: is it worth it? Developmental sequalae of very low birthweight. Pediat Clin North Am 1991; 38: 1497-511.

53 Smith R. The ethics of ignorance. 7 Med Ethics 1992; 18 117-8. 